\title{
Evaluation of Barcelona soil capacity for sorption and degradation of emerging contaminants
}

\author{
MARIA GARCIA-RIOS ${ }^{1}$, GEOFFROY DUPORTE ${ }^{2}$, ELENA \\ GOMEZ $^{2}$ AND LINDA LUQUOT ${ }^{1}$ \\ ${ }^{1}$ CNRS-University of Montpellier \\ ${ }^{2}$ University of Montpellier \\ Presenting Author: mgrios3@gmail.com
}

The fate of emerging pollutants from runoff/storm waters in urban areas has aroused widespread concern as it poses a threat to the water managing. Contaminated water can reach, for instance, the river that passes through the area, contributing to the degradation of the aquatic ecosystem, or the aquifer that supplies drinking water to the community. In this framework, one of the objectives of the URBANWAT project is to evaluate and increase the capacity of the Barcelona urban soil to retain the contaminants of emerging concern from runoff waters in order to propose an improvement of tools and criteria for groundwater management in urban areas.

To this aim, a set of batch and packed soil column experiments were performed. Two different zones of the Barcelona urban area were studied which have different composition of the runoff water (different concentration and type of contaminants and conductivity). Soil composition is quite similar in both sites ( 45 $\%$ quartz, $28 \%$ albite, $-25 \%$ microcline) except for the clay content ( $4 \%$ muscovite in one soil and no clay in the other). A list of representative emerging contaminants has been selected from diverse pharmaceutical family and UV filters. They all have different properties (pka, log Kow, charge,...) that cause them to be sorbed with variable efficiency by the soils tested (90-100\% sorption for Ofloxacin, 40-50\% for Atenolol and 0-10\% for Carbamazepine).

The batch experiments were carried out first to verify if the soils already contained the studied contaminants and second to know the sorption capacity of both urban soils. Different water/soil ratios and contact times were evaluated. By means of the percolation column experiments, the two main retention processes of emerging contaminants (sorption and biodegradation) were quantified together and individually, to verify the specific contribution of each process to the global procedure. The residence time and the solution chemistry have an effect in the remediation process. 